\title{
ICT INEQUALITIES IN THE SPANISH URBAN SYSTEM
}

\author{
Ruben Camilo Lois GONZALEZ, Jose Carlos Macia ARCE, \\ Francisco Jose Armas QUINTA \\ University of Santiago de Compostela, Spain
}

\begin{abstract}
In the current Information Society cities enjoy a privileged position when it comes to transport and communication infrastructures. The post-industrial society has brought with it a notable change, changing from an economy based on the production of merchandise to another based on the production of services. The metropolitan areas act as key areas and markets for predominant sectors, such as finance and specialised services for business. In another way, big cities fulfil new roles in the global economy of the Information society, operating as command points in the world economy. They bring equipment together highly-qualified workers, they are big information and knowledge consumers and have been able to reinvent themselves, changing from industrial to cultural cities. They are, as well, ideal areas for big telecommunication companies and they are, for this reason, those who most benefit from information and communication technology. An important social area difference has then been introduced, with respect to other urban areas of lesser importance, or rather, with respect to rural areas that stay on the margin of the new technology revolution. In this context, it is right to ask what is happening in Spain. Why are ICT inequalities happening in Spain? Are there urban system differences before the arrival of the Information Society? Can it be said that Spanish urban areas are consolidated in the Information Society? In this article we try to outline the reality of the immersion the Information Society in the Spanish urban system, and, in the same way, bring to light a new idea of 'Digital Divide', amongst those sectors of the population that make the most of all or a great part of the potential new technology offers and those that limit themselves to using the most basic functions, such as looking up information and using communication.
\end{abstract}

Key Words: ICT equipment, Information Society, urban system, Spain

\section{Introduction. New urban context in the information society}

The technological revolution which started at the beginning of 1970 gave rise to a new type of society. This technological revolution could be compared to the importance of new sources of energy in the Industrial Revolution, which received different names according to the authors. Castells (2000) defines it as a Net Society or Information Society; Bell (1976) refers to it as a Post-industrial Society, meanwhile other authors such as Serra (1999) calls it a Knowledge Society. Toffler (1996) called this phase "the third wave", suggesting that it would be as important as the previous revolutions. The concept of a Post-industrial Society referred to by Bell (1976) makes reference to the changes in social structure and to the way in which the economy and job market is being transformed. In this new society, companies, limited companies and other types of organisations build networks (Castells, 2000). From these new activities emerge new economies and industries (Mattelart, 2002) which notably increase employment, although this means the destruction of repetitive and bureaucratic jobs.

The transition from the Industrial Society to the Information Society has meant, in an economic aspect, the change from factory work to service work and from physical work to mental work (Fukuyama, 2000). For the first time in history, the human brain has a direct productive strength and not only a decisive element in the production system (Castells, 2000). In the Information 
Society the production is worldwide and the information technology is cheap, thus enabling the movement of information and financial transactions across national borders (Veltz, 1999; Castells, 2000).

With the arrival of the Internet, space-time relationship has narrowed more than ever. There was a rise at work and authors such as Cairncross talked about "The End of Distance", "The Death of Distance", "A World without Distances", "Virtual Space", "The Virtual Community", or "Cyberspace". All of them conclude that we are witnessing a large global opening with the creation of information flow with economic, political, social and cultural communication within a large worldwide net (Short and Kim, 1999). Nowadays, the Internet is the backbone of global communications through the computer, which at the same time connects millions of computer networks including the whole spectre of human communication (Castells, 2000). The development of the Internet not only has a large economic repercussion but also a social and cultural one which has given rise to a large amount of research on its origins and its consequences. Authors such as Serra Hurtado (1999) say that the Internet is the infrastructure for the knowledge society that is about to be designed and built. But the telecommunication infrastructures are not a solution to promote development processes alone (Malecki, 2003; Grimes, 2000), qualified personnel who can make the most of these technologies is necessary. For Serra Hurtado (1999) the challenge will be to know what is to be put in this infrastructure and which society will be developed on this platform. At the same time he asks for a study into whether this new type of society is to be planned, is to be spontaneous, or if it is just to make an impact on that rising society.

In the industrial society, information, technology and knowledge were exclusive to advanced nations, mainly concentrated in the big metropolis and important capitals. When it comes to the information society this situation changes in some aspects, being those of smaller size entities or even those on the rural outskirts having access to huge amounts of information that can generate knowledge and, at the same time, promote development processes. In the same way, the information society can mean a new opportunity for less developed areas and it can also increase the preexistent socioeconomic differences in the industrial age. The unplanned broadcasting boom of the information society generated large areas and social masses unimpressed by the Internet and therefore unaware of the profits and opportunities on offer. In this process the big cities and spaces nearby maintain a hegemonic position in the information society in respect to the small urban centres and rural spaces.

The first phase of the spread of information and communication technology development was in the urban areas (Gutiérrez Puebla, 1998). The arrival of telecommunications is creating a new urban hierarchy led by metropolitan areas with a higher capability to receive and process information (Moss, 1987). It must also be borne in mind that the Internet requires the minimum of infrastructure and this is usually provided by private telecommunication companies which only act in spaces associated to active markets and economic profitability. In this way, the telecommunication market decides which territories are connected to the Internet and which are not. All of this brings with it a large territorial and social breakdown known as "The Digital Gap". This is the exclusion of some communities in the information society. The areas and social groups which are excluded from this emerging society are present in underdeveloped countries as well as developed countries, in rural and urban areas. Sassen (2005) points out that, apart from the Digital Gap, another division in cyberspace is between the populations that have high speed access to the Internet and those who only have a slow Internet connection. Nowadays, this fact stops these social groups having access to most services provided by the net, conditioning its use, and, at the same time, the development of some activities that can favour development processes, such as working from home or electronic commerce. Lastly, 
there is a social group that, in spite of having Internet access, do not use it correctly due to either an insufficient knowledge of how to use the Internet or because they do not find it useful, and, in some cases, for both reasons. Education of the population is therefore necessary if there is to be absolute immersion in the information society as well as information on the opportunities available.

In the current framework of the technology revolution and the technology and communication diffusion process, it is worth mentioning the new functions that are being carried out for the organisation of the world economy in large cities. For Sassen $(2003,2005)$, the big cities are exercising a strategic function due to the growing globalisation of the economy, operating as command points for the world economy. These cities exercise as key places and markets for the predominant sectors, such as finance and the specialised business services. Sassen names these metropolis "Global Cities" for concentrating on highly important resources and where predominant sectors exercise a highly important influence on economic and social order in these settlements. The spread of factories, with some being situated in small urban centres or rural areas thanks to information and communication technology, requires executive management and centralised control from global cities. The rapid growth of the finance sector and specialised services not only generates employment for the highly qualified but also the lowly qualified due to the demand for services from a society with purchasing power (domestic services, cleaning, etc).

In this respect Castells (2000) considers that the global city is a process more than a place. In said process, the production centres and advanced consumer services and local subsidiary associations connect on a global network by way of information flow. According to this author, the global city phenomenon cannot be just reduced to urban centres with a high level of hierarchy. It is a process that implies advanced services, production centres and global network markets, with differing intensity and on different levels. Within each country the network architecture is rendered in regional and local centres, to which effect the system as a whole becomes interconnected on a global scale. For Castells, some of the motives gather the most advanced services in these metropolises. It is the production centres based on information where headquarters of large companies and advanced firms can find both suppliers and a highly qualified workforce. On the other hand, these large firms make big investments when settled in a place and so do not relocate as a result. But also in these spaces there is a considerable sector in the population living in poverty and thereby excluded from the technology revolution and the information society. The most significant thing about these big cities is that they are connected with the outside through global networks and stay disconnected with the inner population that is functionally unnecessary.

From these theoretical and introductory considerations, in this present article a brief diagnosis in the state of diffusion of the information society in the Spanish urban system is carried out through basic equipment indicators and the use of information and communication technology. It is an analysis of ICT equipment and Internet connection in households as well as the use by part of the population in relation to the size of the settlement, with the aim of valuing the state of the implantation of the information society in the Spanish urban area. At the same time, the intention is to research towards a new understanding of the related Digital Gap on the one hand, with those social masses that have unused Internet access, either through a lack of training or because no real use is seen for it or, on the other hand, with groups which, even with already being Internet users, only use the most basic functions, thus forgetting the advanced services the Internet has to offer and can offer, as well as offering a better quality of life for inhabitants, it also promotes economic and social development processes on peripheral areas. 


\section{Methodological notes}

In order to carry out this analysis, sources that provide data on ICT equipment in homes were consulted, as well as inhabitant's access to the Internet. Among them is the survey on equipment and use of information and communication technology in the home which was carried out by the National Statistics Institute (INE); the records provided by the statistics office of the European Union (Euro stat); reports on e-España, published from 2007 by the Orange Foundation, The Media General Study (EGM) which was carried out by the Association for the Research of Media (AIMC), specifically the reports on "Internet Audience" and "Net Surfers".

With the objective of studying the diffusion level of information and communication technology in the Spanish urban system, data from these sources on equipment and the use of information and communication technology in the home from the National Statistics Institute were used. The said survey provides data on equipment and use of ICT according to the size of the councils with the following detailed division: Councils with more than 100,000 inhabitants and province capitals, councils with between 50,000 and 100,000 inhabitants, councils with between 20,000 and 50,000 inhabitants, councils with between 10,000 and 20,000 inhabitants and councils with less than 10,000 inhabitants. Based on the proposed objective, the data provided by this survey was clustered into only three groups. Those councils with more than 100,000 inhabitants and province capitals, representing the biggest urban groups, taking into account the capital's demographic size for each province; councils with between 50,000 and 100,000 inhabitants, which correspond to medium-sized cities; and lastly, councils with between 10,000 and 50,000 inhabitants which would cluster the least important urban groups. The areas with less than 10,000 inhabitants were dismissed for not being considered urban, according to the criterion used by the National Statistics Institute and, for that reason, excluded from our study.

In order to carry out an equipment diagnosis and the use of information and communication technology in the Spanish urban system five indicators were taken; three of them corresponding to ICT equipment in the home, the percentage of homes with computer, the percentage of homes with broadband Internet connection. The other two indicators refer to the use of information and communication technology of inhabitants between 16 and 74 years old, giving information on the number of people who used the net and shoppers on the net in the last three months, with relative values. The reason for choosing these last two indicators is due to the interest in knowing the type of use inhabitants make with these technological tools and to see the level of their potential use. In a parallel way, two more indicators were added resulting from the data provided by the ICT equipment survey and its use in the home, the real and potential users of computers and the Internet. These two indicators give interesting additional information for the study of the use of ICT, because they provide information on the population who do not use this type of equipment even when having access to it, either because they do not have adequate knowledge or because they do not find it useful. Therefore, we see a new concept of the Digital Gap generated by a social mass which has the correct equipment for the information society, but does not take part in it. To obtain data, an estimate of the average number of inhabitants between 15 and 74 was made so that they could be compared with computers users and the net. There is a small difference which does not coincide with the population extract that INE uses for the computer users and the net (from 16 to 74), but unfortunately it has not been possible to adapt data to make quinquennial groups of age to estimate demographic household volume. To calculate the real and potential users of the Internet and to keep the objective of comparing them to home net users, only the data referring to the use of the net from home was taken. At the same time these figures enable us to discover the volume of population who has access to the net from different places to home. If 
we cross these figures with the number of homes with broadband Internet connection, the population's possible infrastructure demand in a particular territory can be known, if there is a high percentage of inhabitants with outside Internet access with a low percentage of broadband use. These last two variables are only calculated in autonomous communities in order to complete the analysis; this is due to the difficulties in obtaining population data by quinquennial age groups in accordance with council sizes.

\section{ICT equipment in the home}

In order to study the equipment for information and communication technology in the home in Spanish urban areas, three basic indicators were analysed: the presence of computers in the home, Internet access and broadband installation, which guarantees the quality of most Internet services.

Nowadays, the computer has become an essential tool and is present in the majority of human activity. Its applications are as varied as they are complex, going from the control of a cash register, tasks from home such as net access, pedagogical resources developed for education, to supercomputers used in science to carry out complex mathematical calculations. Just a few years old, this tool has had a big diffusion in society, companies, institutions and different associations. But, nowadays, there are parts of society who are at a disadvantage with new technologies and disconnected from its emergence.

In reference to the presence of the computer in the home, Spain is around the average for the European Union 15 (64\%), but if the European Union 27 is taken its position improves because the average goes down to $60 \%$, according to data published by Euro stat for 2009 . But, in spite of this, Spain has big differences between autonomous communities and settlement sizes. When referring to the differences between autonomous communities, the values of Cataluña, Madrid, and Navarra stand out, because the data of homes with computer is above $70 \%$ according to the INE data in 2009. On the other hand, there are the communities with the lowest figures in this indicator, Extremadura and Galicia, which do not reach $60 \%$ of homes with computer. Therefore, there is a direct correlation between income levels and the use of the computer because if the first three's GDP per capita values rise to thirty points above the national average, the last two communities have up to thirty points below the national average.

If we take the data in terms of settlement size and analyse the aims of computer penetration in the Spanish urban system then certain differences that are not common to all regions appear. On one hand, there are the communities which have the biggest size settlements, those that surpass 100,000 inhabitants and province capitals, those registering the highest values in terms of household computer penetration, corresponding to larger size cities. Some examples are Extremadura, Canary Islands, Castilla and Leon, among others. In these communities over $72 \%$ of households possess computers in settlements of over 100,000 inhabitants while settlements of between 50,000 and 10,000 inhabitants show a figure of around $60 \%$. The most positive figures among the cities in these autonomous communities are Las Palmas in Gran Canarias, Santa Cruz in Tenerife, Valladolid, Burgos, Salamanca and Albacete, among others. On the other hand, there are communities with medium and small cities which show higher values of computer penetration in the home. This is the case of Catalonia, Madrid, Galicia, Navarra, Asturias and Cantabria. A prime example of this situation is the Madrid case, registering an average of almost $73 \%$ in the presence index of household computers but the settlement size should be taken into account, in councils of between 50,000 and 10,000 inhabitants the figures are around $77 \%$ and in those of between 50,000 and 100,000 the figures are over $81 \%$. In the case of the Madrid Community, the greatest presence of 
computers can be found in homes of small and medium cities such as Coslada, Las Rozas, Pozuelo de Alarcon and San Sebastian de los Reyes. These are predominantly uncongested middle-class residential areas. The bigger cities such as Madrid itself, Mostoles or Alcalá de Henares have lower indexes due to the fact that Madrid has a higher level of aging in the population and, in the case of Mostoles or Alcala de Henares, the working class prevails in the social structure (see Fig.1).

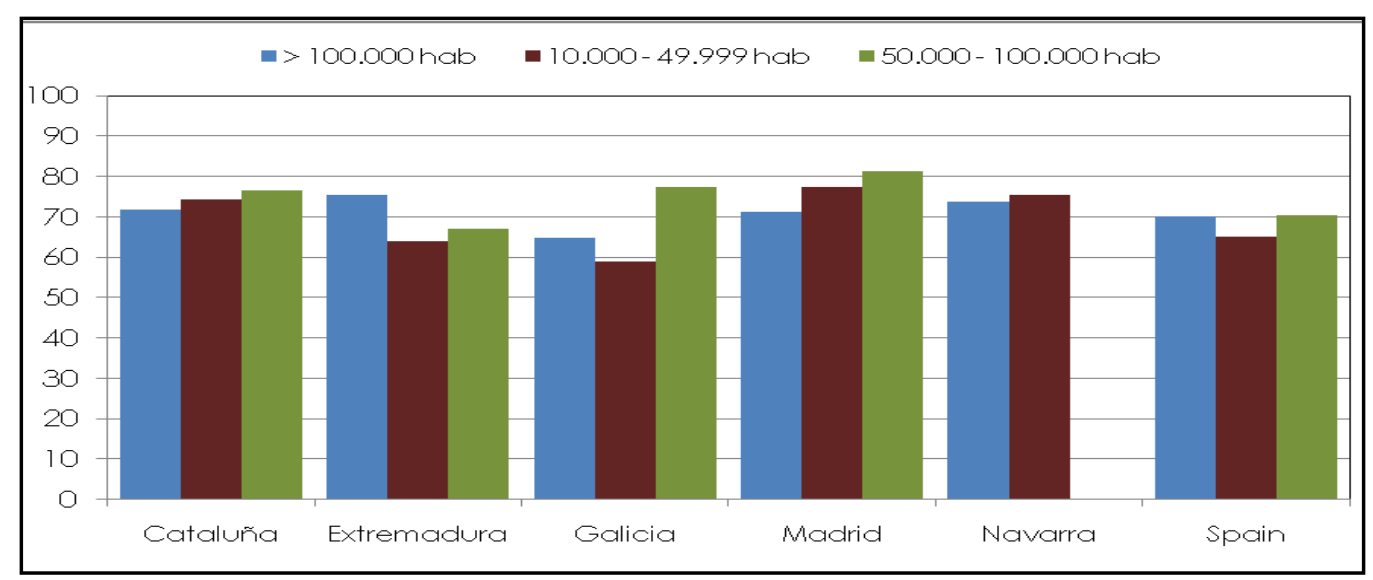

Fig. 1 - Computer Presence in Households 2009 (\%)

(Source: INE, 2009)

Other indicators analysed in ICT equipment in the home are the Internet connections. The information and communication technology, specifically the Internet, enables instant communication and information exchange in any part of the world, however distant they may be, as long as they dispose of the appropriate infrastructure and equipment. In this way, times are reduced to a minimum thus territories that were once disadvantaged now have greater chances to develop should they take advantage of it. However, this is a fairly new process so not all the territories or even all society is immersed in the Information Society, hence, the phenomenon known as the "Digital Gap". This phenomenon separates those people and spaces that are frozen out of this global world.

The presence of the Internet and its complete immersion in the Information Society in Spanish homes is currently a pending subject. If the proportion of households with computers is around the European Union 15 average, the values for Internet presence is much more alarming with various at fault in different Spanish regions. The average household with Internet connection is nine percentage points below the European Union 27, which rises to fourteen if the European Union 15 is taken as a reference, being at the bottom of the table of nations, far off are the leading nations in the Information Society such as The Low Countries, Denmark and Sweden, with $80 \%$ of households having Internet access. In the case of Spain, and taking into account its delayed diffusion of new technologies, a big disparity is found in the percentage points between the community with the most households with Internet connection, as is the case with Catalonia (64\%) and the least, Extremadura (41\%). It has to be said that Catalonia has a higher proportion of urban population as well as considerably higher values of GDP per capita than Extremadura. These factors determine the type of new technologies as well as the telecommunication infrastructures providing Internet access. 
Taking this situation into account, the analysis of Internet in the home based on council size sees the same phenomenon as the household computer case. There are various regions where the demographic size is directly proportional to the number of homes connected to the Internet, the communities of Murcia, Extremadura, Andalucia, Castilla Leon, and Castilla La Mancha, among others. One example is the case of Castilla la Mancha. In this community more than $61 \%$ of homes are connected to the Internet in towns of more than 100,000 inhabitants and province capitals, seven percentage points above the Spanish average. On the other side of the coin are the smaller towns with 10,000 to 50,000 inhabitants where only $44 \%$ of homes have this service, thus being thirteen percentage points below the national average. Therefore there would be substantial differences between cities such as Albacete, Toledo, Guadalajara and the other smaller, less important urban centres in the community, (see Fig. 2), following the classic model of innovation diffusion from the main cities to the other complementary centres in the urban system.

Instead, in other regions the situation is the reverse, where small and medium urban areas present more positive values in this register. This happens in the greater part of the country's autonomous communities, with Madrid, Catalonia and Aragon once again standing out. In the case of Catalonia there are twelve percentage points between the councils with 10,000 to 50,000 inhabitants, where almost $75 \%$ of home have Internet connections and those with more than 100,000 inhabitants with little more than $62 \%$. Hence, small and medium urban centres such as Vic, Olot, Lloret de Mar and Sitges, among others, are better placed in this indicator than any of the four regional capitals (see Fig. 2). The first two centres have high income families while the other two are clear tourist destinations, thus positively influencing the diffusion of ICT equipment in the home. This situation is repeated if the indicator is broadband Internet connection. There are two new situations, the regions with high volume demographic urban centres and province capitals provide more favourable values, and, on the other hand, the regions with medium and small size hold an advantageous position in the information society's immersion process.

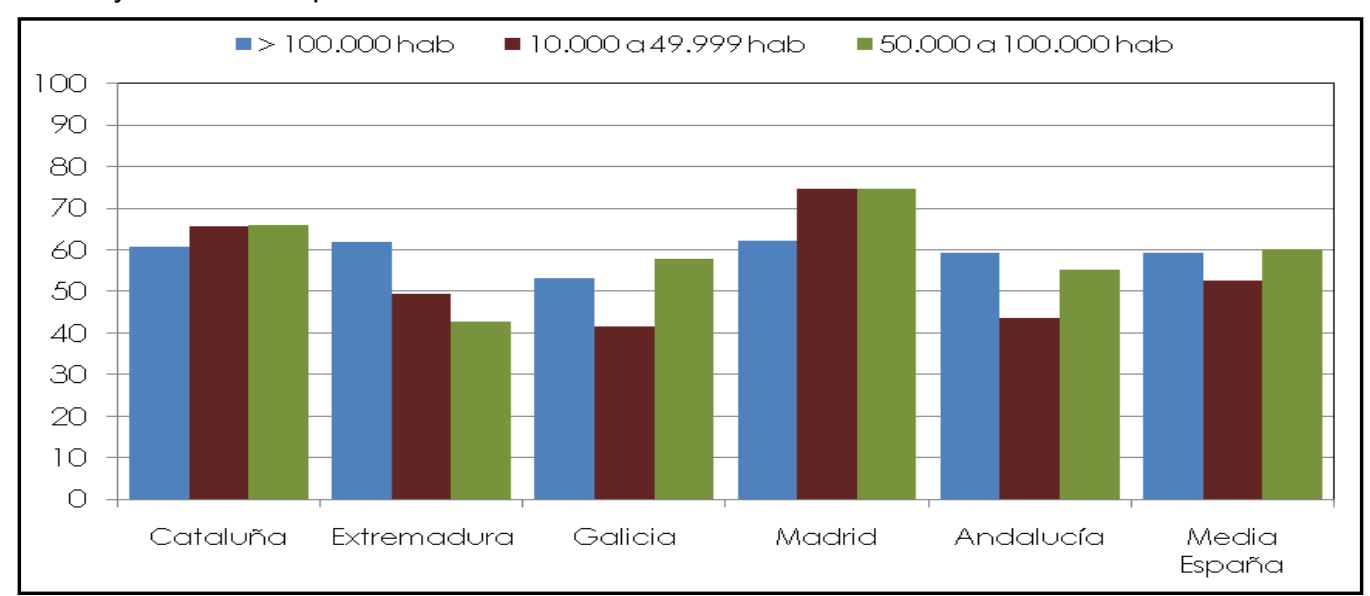

Fig. 2 - Internet Presence in Homes 2009 (\%)

(Source: INE, 2009)

This duality mentioned previously can be down to, in good measure, the growing demography of the urban centres situated in the vicinity of large cities or in centres that, although leaving the urban belt, are well connected and enjoy remarkable public service equipment. This growth is 
owing to the population's attraction to move from big cities to smaller urban centres in search of cheaper dwellings and a better quality of life. This sector of the population are usually young inhabitants with higher or lower qualifications as well as middle class and professions choosing to reside in these medium urban centres, whilst, at the same time, demanding the services of the information society. In the case of Madrid, in the ten fastest growing councils in the last ten years (1999-2009), six of them have less than 100,000 inhabitants and more than 10,000. Together with this, of all the smaller urban councils, those of between 10,000 and 50,000 inhabitants, more than $80 \%$ registered a positive vegetative growth in 2008 . In view of this data, it can be said the medium and small urban areas of some autonomic communities provide a certain power of attraction for new inhabitants. On the other hand, two large groups can be seen to be frozen out of new technologies in the information society: the elderly population and the illiterate, unqualified. Madrid City has an elevated elderly population $(18.6 \%)$ and an unqualified population (12\%) in comparison to smaller cities located in the greater Madrid urban area. For instance, in the locality of Tres Cantos the percentage is $7.25 \%$ and $2.3 \%$ respectively. The unqualified population in Madrid City is linked to the large influx of immigrants over the last ten years, according to sources from the INE, representing $17.4 \%$ of the council's population. The foreign population in the small localities of the Madrid metropolitan area does not usually reach $10 \%$ of the council's population (see Table 1, Fig. 3 and 4).

Table 1

Population and ICT register in the Madrid Community

\begin{tabular}{|l|r|r|r|r|r|r|r|} 
& Population & Foreigners & Elderly & Unqualified & Computer & Internet & Users \\
\hline Madrid & $3,255,944$ & 17.42 & 18.66 & 12.01 & 71.3 & 62.1 & 66.5 \\
\hline Tres Cantos & 41,064 & 8.56 & 7.25 & 2.31 & 81.6 & 76 & 88.2 \\
\hline Pozuelo & 82,428 & 10.67 & 11.05 & 6.13 & 81.3 & 74.7 & 63.9 \\
\hline S. S. Reyes & 75,912 & 13.00 & 9.29 & 9.83 & 81.3 & 74.7 & 63.9 \\
\hline Las Rozas & 86,340 & 11.71 & 7.89 & 3.30 & 81.3 & 74.7 & 63.9 \\
\hline
\end{tabular}

Source: Madrid Community Statistics Institute, 2009, 2001; National Institute of

Statistics, 2009.

Note: Total Council population (IEM, 2009); Percentage of foreigners in the council's population total (IEM, 2009); Elderly population in the council (IEM, 2009);Illiterate and unqualified population (IEM, 2001); Households with Internet connection (INE, 2009); Households with Internet connection (INE, 2009); Internet users in the last three months (INE, 2009).

\section{The use of ICT in the urban sector}

From the moment that the Internet became popular and large masses began to have access to the Internet, the fundamental uses were limited to electronic mail exchange and the search for information. Nowadays there are many Internet services on offer, either from the public administration or from the private sector. The types of services range from a simple hotel reservation or weekly shopping on a supermarket site to multiple and varied administration processes. But, in spite of the availability of this type of service the statistics reflect that citizens still make very little use of the service, hence, leaving a long way to go in this respect. The strong growth seen in the number of Internet users in the last ten years has not gone hand in hand with the use of this type of service. 


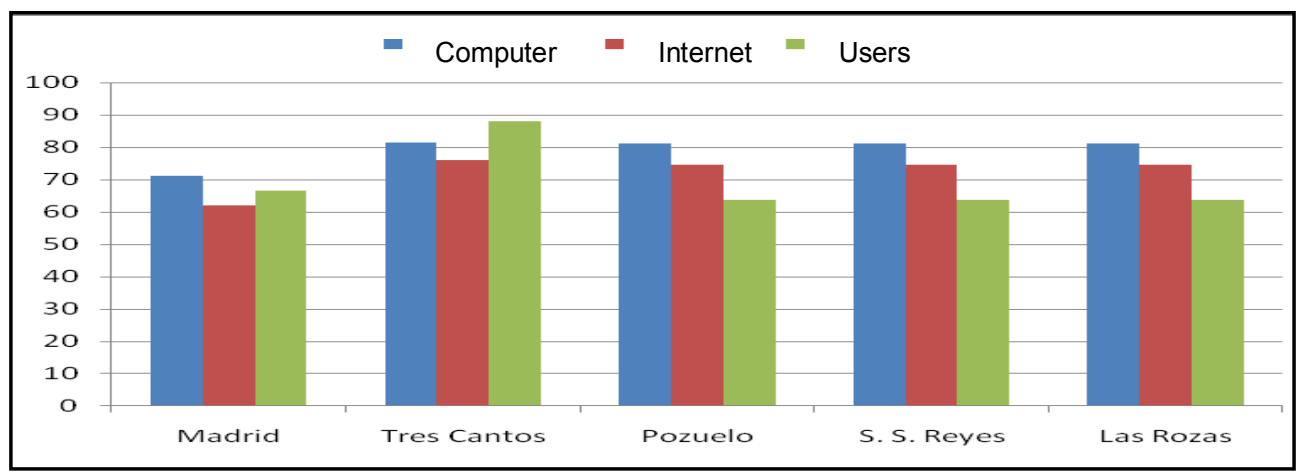

Fig. 3 - ICT registers in the Madrid Community, 2009 (Source: INE, 2009)

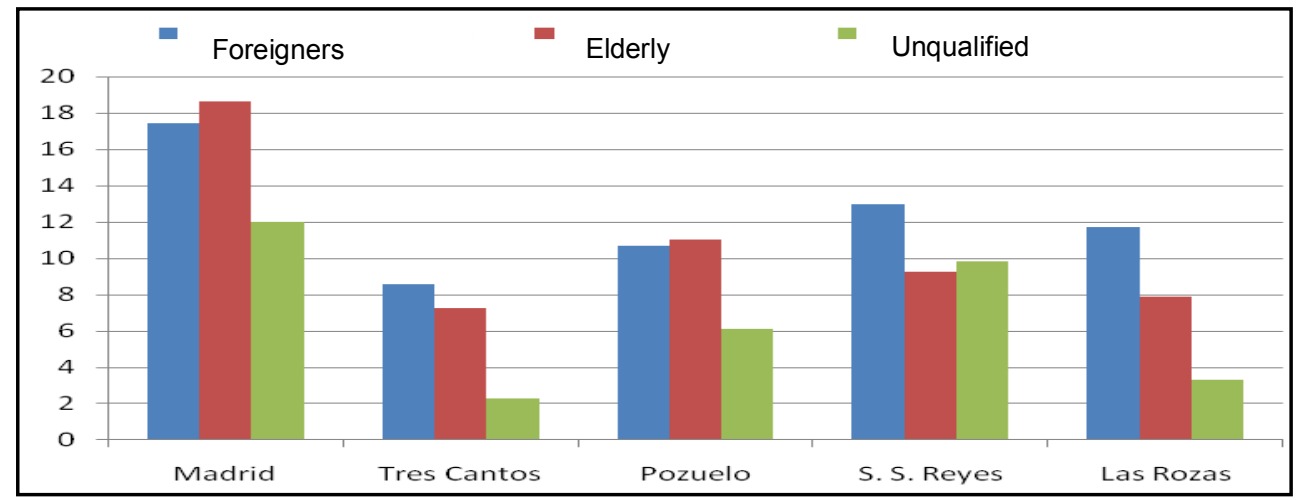

Fig. 4 - Demographic registers in the Madrid Community, 2009 (Source: INE, 2009)

In a European context, Spain is near the bottom in the use of the Internet table, following the same tendency as that of ICT equipment in the home. The average number of Internet users does not reach $60 \%$ of the population between 16 and 74 in 2009, according to The National Institute for Statistics, being the average for the European Union 27, 65\% and for the 15, 69\%. Spain would therefore be almost ten percentage points below the European Union 15 in respect to Internet users, a long way off the leading countries in the diffusion of the Information Society, such as Sweden, where 9 out of 10 inhabitants between 16 and 74 are Internet users. A similar situation can be found in the Low Countries, Denmark and Luxembourg where more than $85 \%$ of the population uses the Internet.

The Spanish delay in the European context new technologies diffusion reveals important disparities between the respective regions owing to, in part, the differences in economic and social dynamics. There are twenty percentage points between the autonomic communities with highest and lowest number of Internet users. Occupying the first places are Madrid, Catalonia, Navarra and the Balearic Islands with more than $65 \%$ of their inhabitants between 16 and 74 being Internet users. The other side of the coin is Extremadura and Galicia, where Internet users do not reach $50 \%$ (see Fig. 5). 


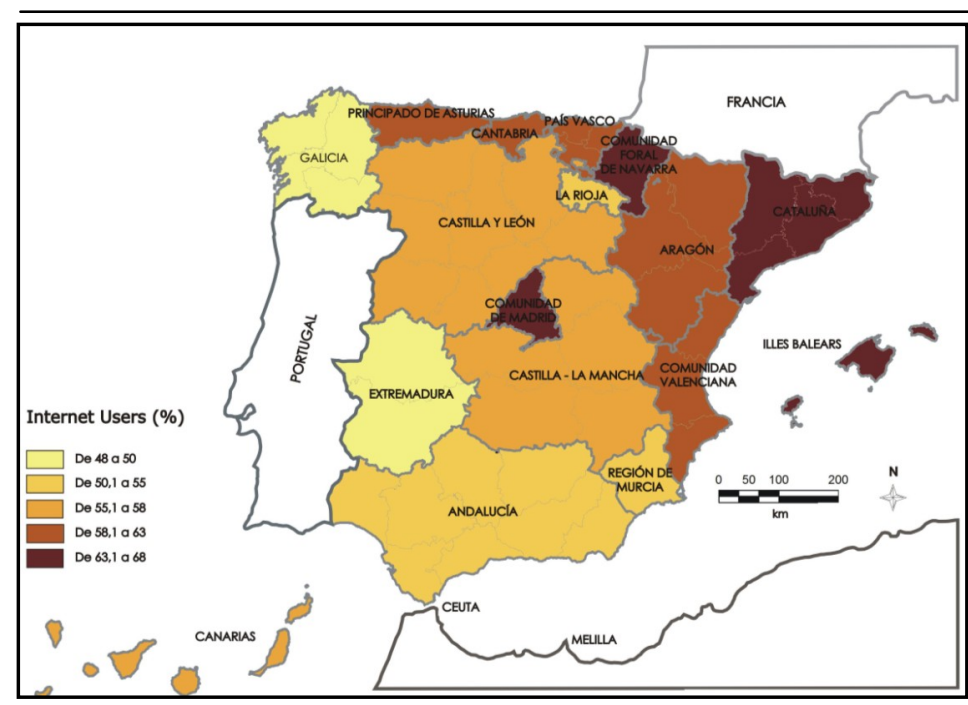

It must be taken into account that the richest communities are those that have the most positive values in Information Society diffusion. In fact, the Basque Country, Navarro and Madrid are between 25 and 30 percentage points above the national GDP average per inhabitant while Andalucia, Castilla la Mancha and Galicia are between 15 and 22 points below the average (see Fig. 6). Given these figures it is evident that it is necessary

Fig. 5 - Internet users in Spain, 2009 (Source: INE, 2009) to develop realistic initiatives that achieve great advances and enable a convergence process in both the different Spanish regions and the different countries that make up the European Union. On a national level there have been various diffusion plans for the Information Society but the majority have not achieved their objectives. On the other hand, communities bringing up the rear, such as Galicia, were the last to design this type of measure, thus some time will have to pass for the proposed objectives to be achieved.

In the analysis of Internet users according to council size, a similar dynamic is noted with that of ICT equipment in the home, although in this indicator, the largest urban areas have a higher proportion of Internet users. In this case, it is not necessary to have a home Internet connection to make use of Internet services. In those urban centres with a larger public access offer there could be a higher use of the Internet. If in homes with Internet connections there were ten council regions with small size urban areas and higher positive values, then in the terms of Internet users this reduces to four. The most

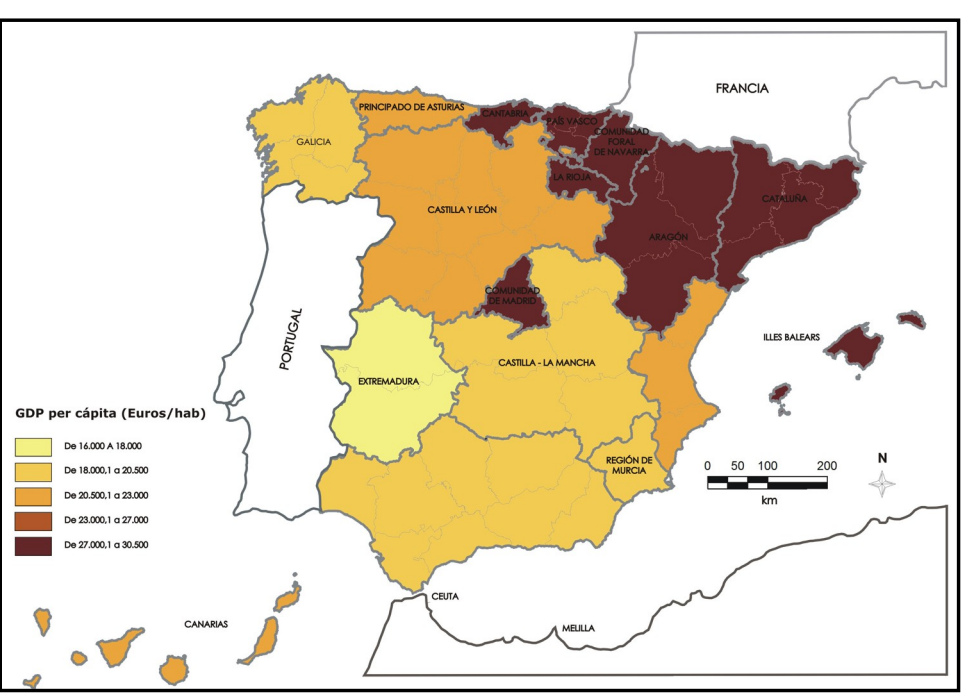

Fig. 6 - Income per capita in autonomic communities in Spain (Euro/hab.) (Source: INE, 2009) 
prominent is in the community of Madrid and Castilla la Mancha and, to a lesser extent, Galicia and Catalonia. In Madrid the councils with towns of lesser entity in the region, providing home to between 10,000 and 50,000 inhabitants have an $80 \%$ Internet user rate in the population aged between 16 and 74 , some 13 percentage points above the councils of more than 100,000 inhabitants. In Castilla la Mancha the situation is similar but here the urban areas are mediumsized. These are councils of around 50,000 to 100,000 inhabitants who have more Internet users, around more than $75 \%$ of the 16 to 74 year old population, some 10 percentage points above councils of more than 100,000 inhabitants. In view of this information, and in the case of this community, the urban centres of Talavera de la Reina and Puertollano have a larger proportion of inhabitants using the Internet than in the province capitals. On the other hand, it should be taken into account that in Castilla la Mancha, four out of five province capitals have less than 100,000 inhabitants and are included within the group of large size councils. The other two cases are Galicia and Catalonia. In Galicia, the values of Internet users in councils of between 50,000 and 100,000 inhabitants surpass by six percentage points those of large size, although these conditions are only met in the cities of Santiago de Compostela and Ferrol. Lastly, in Catalonia the situation is similar. It has the same values for Internet users in the largest and the smallest councils, with $65 \%$ of the population Internet users. The medium-sized urban areas of this region are better situated in this respect although there are not great differences as in the cases of Madrid or Castilla la Mancha.

These differences between the behaviour of ICT equipment and net user figures in terms of settlement sizes could be down to the fact that it is not necessary to have a home Internet connection to surf the net. There is a proportion of the population that connects to the Internet outside the home, be it at the work place or the place of study etc. The motives can be varied; from the impossibility of having a broadband Internet connection to simply not considering it necessary. In this respect, the autonomous communities are those who carry most of the blame for the delay in the implantation of the information society, being these communities that have the highest proportion of users connecting from outside the home. In Extremadura, Castilla la Mancha, Murcia and Andalucia one out of four people have connected from outside the home in the last three months. This situation is different in the communities of Madrid, Catalonia and the Balearic Islands where more than $85 \%$ of Internet users connect from home. Among the Internet users connecting from outside the home, a near $60 \%$ do so from their place of work or study, $28 \%$ from a family or friend's home and around $10 \%$ connect from public libraries. This brings into play the fact that ICT equipment behaviour patterns do not correspond to settlement size as it does not follow the identical tendencies of that of Internet users.

The diffusion of information and communication technology delay in Spain is still more evident if the use of Internet services that go further than just consultation or information exchange is taken into account. If in the other indicators studied Spain was at the bottom then the figures on people making Internet purchases only confounds this situation. According to Euro stat data for 2009, in the European 27, 28\% of net users made Internet purchases while if the European 15 is taken into account then that figure increases to $33 \%$. In the Spanish case, and taking data from the National Statistics Institute, only $15 \%$ of Internet users made Internet purchases. On analysing this data in function of settlement size it can be seen that no type of tendency is followed, contrary to the other indicators studied. An example of this is Extremadura which has lower values of ICT equipment in the home and in net users. In these indicators the bigger settlements register more positive values whilst users making Internet purchases come from the medium and small urban councils. In the same way, there are other regions where the same behaviour as the rest of the indicators can be observed, as is the case with the communities of Madrid and Barcelona. This situation can be down to the low proportion of Internet users using the net specifically for this service and, possibly, there will have to be a 


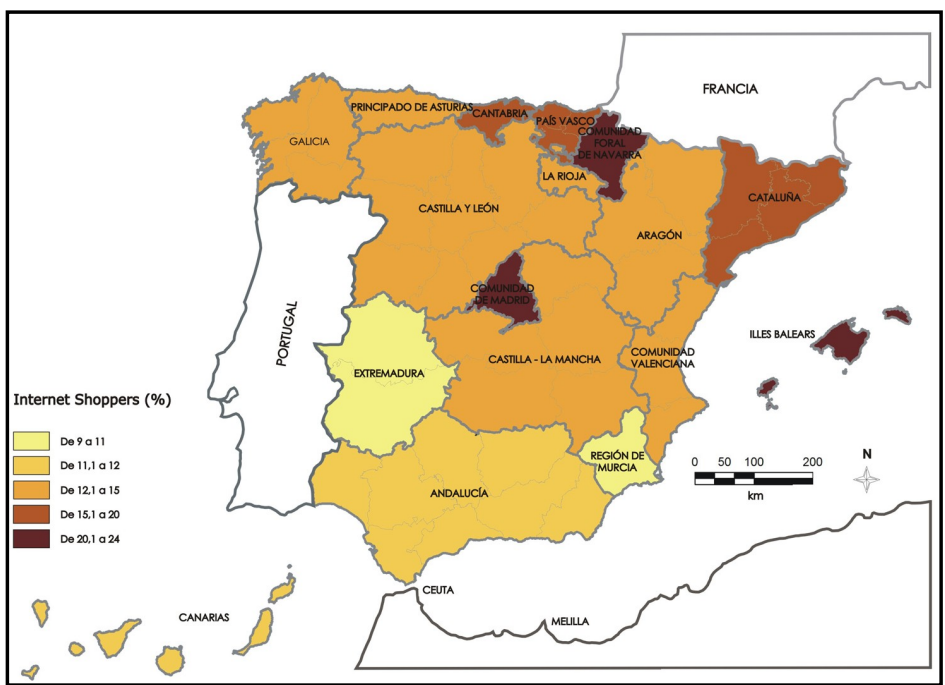

Fig. 7 - Internet shoppers, 2009 (Source: INE, 2009)

substantial wait for Internet surfers to make use of this and other Internet services before a study on behaviour patterns in function of urban area size can be carried out (see Fig.7).

The gap in the "Digital Home".

The concept of the Digital gap arose at the hand of the III Technological Revolution. The birth of the Internet and the potential this type of technological tool has to offer has left a part of the population frozen out (Sassen, 2005;

Castells, 2000; Serra, 1999). Many governments have tried to palliate these inequalities with various plans to foster infrastructure construction, the provision of computers and household Internet connections, education centres, in administration and the business sector. Regardless of the amount of success achieved, there must a reflection on the importance and the need to educate citizens for their full integration into this emerging society until the population can make use of this technology to the full and go beyond the simple consultations and information exchange. On one hand, it is needed that the population make use of existing Internet services and, on the other hand, that both the public and private sectors create new services with the aim of improving the population`s quality of life.

The use of ICT equipment in the home analysis detected that a part of the population has the equipment and the infrastructure for Internet access but does not connect. Therefore, there are two types of Internet user in the home: the potential and the real. The first are all those people who live in "connected homes" and that can access Internet when they want. The real users are those who actually make use of the equipment. This means that there is a bulk of the population that does not use either the ICT equipment or the Internet even when the equipment is available to them, either because they do not have the essential knowledge to use it or they simply see no use for it. This sector of the population would form part of the new Digital Gap dimension, the "The Digital Gap in the Home".

In the Spanish case this type of the Digital Gap was analysed on an autonomous community level, it being difficult to find data to calculate this function on council size. On average, in Spanish homes $8 \%$ of the population between 16 to 74 years old have computers but do not use them and $19 \%$ of these possess an Internet connection but do not use it. There are considerable differences between autonomous communities, ranging from $14 \%$ of inhabitants possessing computers and not using them in the Canary Islands to $3 \%$ in Valencia. In the case of Internet use, the digital gap is much higher inasmuch as more than $20 \%$ of the inhabitants in ten communities have the possibility to access Internet in their homes and do not do so. Heading the list is Extremadura, Castilla la Mancha and Murcia with more than $25 \%$. Madrid and Catalonia are the regions where this phenomenon is less felt. Given these figures, building 


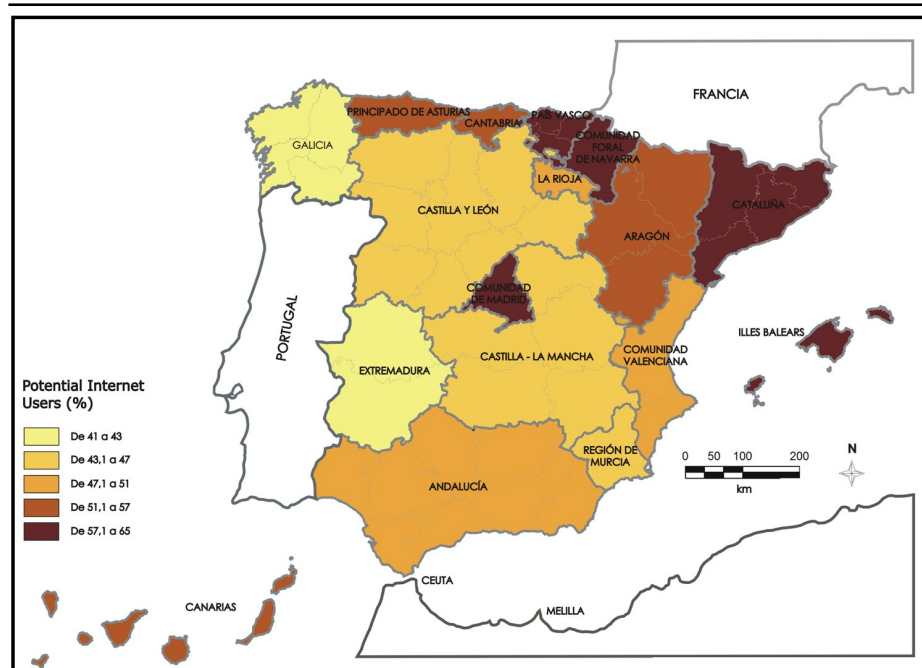

Fig. 8 - Potential internet users, 2009 (Source: INE, 2009)

measures are needed to encourage this population stratum, with possibilities of full immersion as the objective (see Fig.8).

\section{Conclusions}

The analysis result of the information society immersion process in Spanish urban areas has evidently shown the delay the country has suffered as a whole in respect to leading countries in the diffusion of the information society. Similarly, this situation has been accompanied by a series of regional disparities that, in spite of a positive evolution in the last few years, still has not lead to a process of convergence between the main new technology diffusion indicators. In this context, and observing what the situation is like in Spanish urban areas, a duality in the level of ICT equipment and Internet users is detected. There are a group of regions, with Madrid and Catalonia standing out, where small and medium urban areas present more positive values. In the rest, the demographic capacitance in the urban areas is directly linked to equipment values and the use of ICT. This duality can be blamed on demographic growth in urban centres located on the edge of large cities or in centres that, although outside the urban belt, are well connected to the city and dispose of good public service equipment. Similarly, the sociodemographic make up of the cities must not be neglected as this conditions the use of new technology. As previously stated, there are small and medium cities with a high proportion of homes with computer, broadband connection and Internet users. These are urban, uncongested residential centres, demographically young with a high proportion of middle-class and professions in the population. On the other hand, there are large central cities with lower values in the use of new technology being that the level of the elderly population is higher and there is a greater diversity in the socio-professional structure of the population.

This behaviour pattern breaks when it comes to the number of Internet users shopping on the net. In this case, communities such as Extremadura, where the demographic size is a conditioning factor in the ICT diffusion, the situation is reversed, being the small and medium areas where the highest number of Internet shoppers are registered and have been conditioned by the relative isolation from large retail centre commerce. Lastly, the impact of the Digital Gap should be pointed out. It manifests in those who have ICT equipment and an adequate Internet connection but do not use it through a lack of sufficient knowledge or because no use is seen for it or both in some cases. Measures are needed to be taken to stimulate the use of this type of tool with the aim of the population making the most of the opportunities the information society has to offer.

\section{Bibliography}

BELL D. (1976), El advenimiento de la sociedad post-industrial: un intento de prognosis 
social, Alianza, Madrid $578 \mathrm{p}$ $645 \mathrm{p}$.

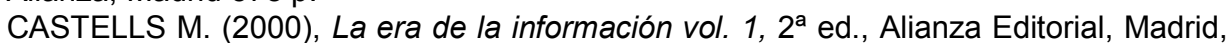

CRANG M., CRANG Ph., MAY J. (1999), Virtual geographies: bodies, space \& relations, Routledge, London, $322 \mathrm{p}$.

GIDDENS A. (2005), Un mundo desbocado: los efectos de la globalización en nuestras vidas, Taurus, Madrid, $117 \mathrm{p}$.

GUTIÉRREZ PUEBLA J. (1998), Redes, espacio y tiempo, Anales de Geografía de la Universidad Complutense, 18, p. 65-86.

GRIMES S. (2003), The digital economy challenge facing peripheral rural areas, Progress in Human Geography, 27, 2, p. 174-193.

GRIMES S. (2000), Rural areas in the information society: diminishing distance or increasing learning capacity?, Journal of Rural Studies, 16, p. 13-21.

HARVEY D. (1973), Social Justice and the City, Edward Arnold, London.

HELD D. MCGREW A. (2003), Globalización-Antiglobalización. Sobre la reconstrucción del orden mundial, Paidós Ibérica, Barcelona, $187 \mathrm{p}$. $282 \mathrm{p}$

KELLERMAN A. (2002), The Internet on Earth, John Wiley \& Sons Ltd., Chichester,

MALECKI E. J. (2003), Digital development in rural areas: potentials and pitfalls, Journal of Rural Studies, 19, 2, p. 201-214.

MATTELART A. (2002), Historia de la sociedad de la información, Paidós, Barcelona, $193 \mathrm{p}$.

MOSS M. L. (1987), Telecommunications and international financial centres, in BROTCHIE J.F., HALL P., NEWTON P.W. (Eds.): The spatial impact of technological change, Croom Helm, Beckenham, p. 75-88.

RAMONET I. et al. (2005), Frente a la razón del más fuerte, Galaxia Gutenberg, Barcelona, $151 \mathrm{p}$.

RENNIE SHORT J., KIM Yeong Hyun (1999), Globalization and the City, Longman, Harlow, Essex9.

ROBERTSON R. (2005), 3 olas de globalización. Historia de una conciencia global, Alianza Editorial, Madrid, $390 \mathrm{p}$.

SASSEN S. (2003), Los espectros de la globalización, Fondo de Cultura Económica, Buenos Aires, $276 \mathrm{p}$.

SASSEN S. Nuevas tecnologías y el poder de los sin poder, in: El Mundo [en liña]. 8 de febreiro de 2005. [ref. de 10-02-2006]. Dispoñible na Internet:

http://www.elmundo.es/navegante/2004/05/18/entrevistas/1084872101.html.

SERRA HURTADO A. Tres claves para entender el fenómeno Internet, La Factoría [en

liña]. Febreiro de 1999, $\mathrm{n}^{\circ} 8$ [ref. de 10-02-2006]. Dispoñible na Internet: http:// www.lafactoriaweb.com/articulos/serra.htm.

TOFFLER A. (1996), La tercera ola, Plaza \& Janés, Barcelona, 661 p.

TOURAINE A. De la economía global a la guerra regional, Foro Complutense. Fundación General UCM [en liña], 2002, [ref. de 13-02-2006]. Dispoñible na Internet: http:// www.ucm.es/info/fgu/foro/articulos2t3.htm.

VELTZ P. (1999), Mundialización, Ciudades y Territorios, Ariel, Barcelona.

Received at : 8.11.2010

Revised at: 06.12.2010

Accepted for publication at: 15.12 .2010 